\title{
Duodenal Metastasis from Head and Neck Cancer with an Intestinal Obstruction
}

Katuyoshi Ando, Mikihiro Fujiya*, Nobuhiro Ueno, Katsuya Ikuta and Yutaka Kohgo

Division of Gastroenterology and Hematology/Oncology, Department of Medicine, Asahikawa Medical University, Japan

\begin{abstract}
Small intestinal metastasis from head and neck tumors is very rare. We herein report the case of a 71-yearold male with severe duodenal stricture due to duodenal metastasis from head and neck cancer whose duodenal stricture was conservatively relieved by endoscopic stenting. The patient had been treated with total laryngectomy and postoperative radiotherapy 13 months before visiting our department with complaints of a loss of appetite and vomiting. Esophagogastroscopy revealed a large submucosal tumor with severe obstruction in the duodenum. The histological findings of biopsy specimens showed moderately differentiated squamous cell carcinoma. He was thus diagnosed to have duodenal metastasis from the original supraglottic larynx cancer. Because his general condition was not sufficient to allow additional chemo-radiotherapy or surgery to be performed, conservative endoscopic stenting was employed to relieve the obstructive symptoms. After the stenting, the symptoms all immediately disappeared. When patients with head and neck tumors present with gastrointestinal bleeding and/or symptoms such as intestinal obstruction, endoscopic stenting appears to be useful for the palliative relief of such symptoms.
\end{abstract}

Keywords: Duodenal metastasis; Head and neck carcinoma; Intestinal obstruction; Endoscopic stenting

\section{Introduction}

Distant metastasis after the initial treatment of head and neck cancers is closely associated with a poor prognosis $[1,2]$. While the most common sites of the distant metastasis of head and neck squamous cell carcinoma are the lungs, followed by the bone and the liver [3-7], only a few cases of metastases in the small bowel have been reported [811]. The mechanism underlying distant metastasis is considered to be associated with the microenvironment of certain organs, as well as the lymphatic and vascular drainage pattern from the site of the primary tumor $[12,13]$. We herein report a case of duodenal metastasis from supraglottic laryngeal cancer with a severe intestinal stricture that was successfully treated by endoscopic stenting.

\section{Case Report}

A 71-year-old male, who was diagnosed with supraglottic laryngeal cancer with bilateral neck nodal metastases and had been treated by total laryngectomy and post-operative radiotherapy 13 months before, was admitted to our department complaining of a loss of appetite and vomiting. Six months before this admission, lung metastasis had been detected by computed tomography, but the oral administration of 5-fluorouracil had reduced the size of the lung metastasis and the tumor progression had been inhibited until the present episode. The patient had smoked 40 cigarettes/day for 40 years, but had not consumed any alcohol. He had no history of diabetes, hypertension, hematemesis or melena. His blood pressure was $103 / 52 \mathrm{mmHg}$ and his pulse rate was $81 /$ minute. A blood examination revealed low levels of white blood cells $(1470 / \mu \mathrm{l})$, hemoglobin $(7.6 \mathrm{~g} / \mathrm{dl})$, total protein $(5.2 \mathrm{~g} / \mathrm{dl})$ and albumin $(3.2 \mathrm{~g} / \mathrm{dl})$.

Esophagogastroscopy revealed a large submucosal tumor with a severe circumferential obstruction in the second portion of the duodenum (Figures 1 and 2). The histological findings of biopsy specimens obtained from the submucosal tumor contained moderately differentiated squamous cell carcinoma (Figures 3-5). Therefore, the patient was diagnosed with a duodenal metastasis from supraglottic laryngeal cancer. Computed tomography revealed

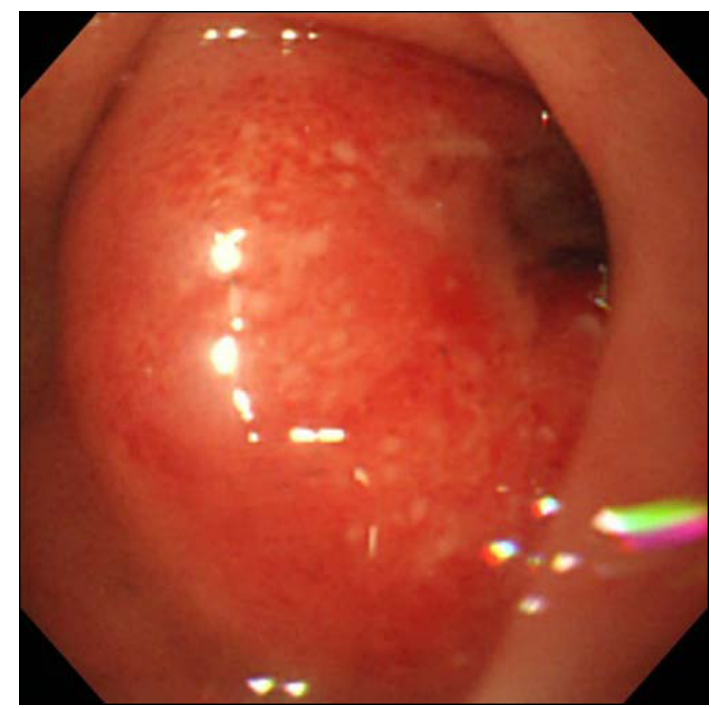

Figure 1: Endoscopic images of the duodenal metastasis from supraglottic laryngeal cancer.

Esophagogastroscopy detected a large and smooth-surfaced submucosal tumor with no ulceration. These findings suggested that the lesion was not originated from the duodenal epithelia, and might be a metastatic tumor.

*Corresponding author: Mikihiro Fujiya, Division of Gastroenterology and Hematology/Oncology, Department of Medicine, Asahikawa Medical University, Asahikawa, Japan, Tel: +81-166-68-2462; Fax: +81-166-68-2469; E-mail: fjym@asahikawa-med.ac.jp

Received October 25, 2014; Accepted November 13, 2014; Published November 15, 2014

Citation: Ando K, Fujiya M, Ueno N, Ikuta K, Kohgo Y (2014) Duodenal Metastasis from Head and Neck Cancer with an Intestinal Obstruction. J Cytol Histol S4: 016. doi:10.4172/2157-7099.S4-016

Copyright: (c) 2014 Ando K, et al. This is an open-access article distributed under the terms of the Creative Commons Attribution License, which permits unrestricted use, distribution, and reproduction in any medium, provided the original author and source are credited. 
Citation: Ando K, Fujiya M, Ueno N, Ikuta K, Kohgo Y (2014) Duodenal Metastasis from Head and Neck Cancer with an Intestinal Obstruction. J Cytol Histol S4: 016. doi:10.4172/2157-7099.S4-016

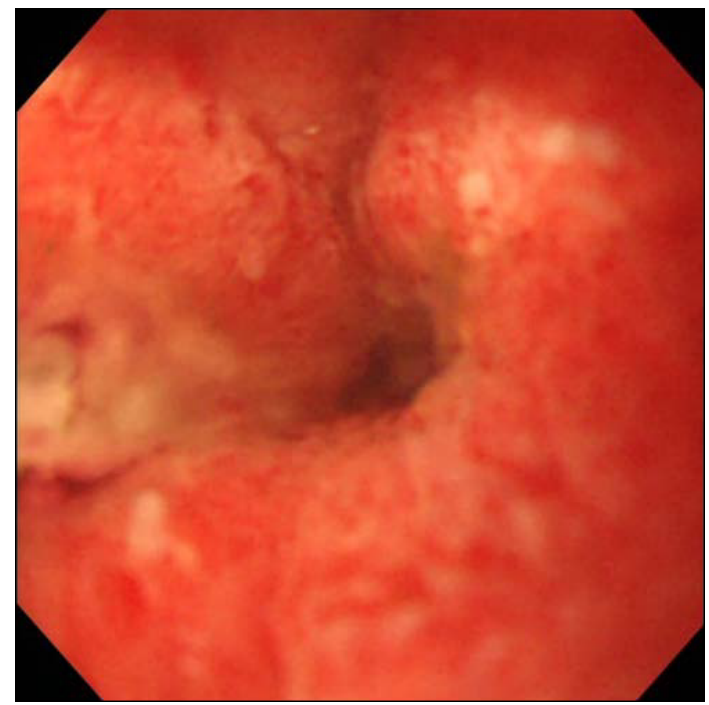

Figure 2: Endoscopic images of the duodenal metastasis from supraglottic laryngeal cancer.

A $3 \mathrm{~cm}$-long circumferential obstruction was observed from the duodenal bulb to the second portion of the duodenum. These findings suggested that the lesion was not originated from the duodenal epithelia, and might be a metastatic tumor.

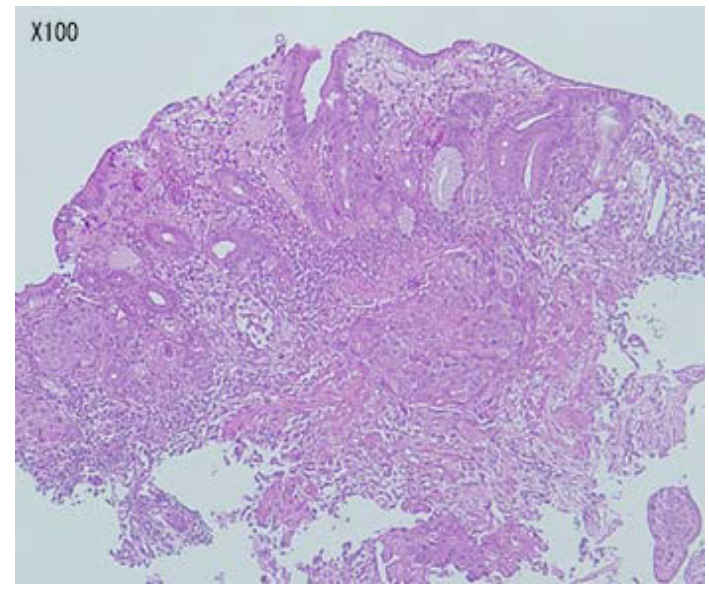

Figures 3: The histological findings of the duodenal metastasis from supraglottic laryngeal cancer. The histological findings of biopsy specimens obtained from the submucosal tumor showed moderately differentiated squamous cell carcinoma forming an alveolar pattern with an enlargement of the nucleus in tumor cells and a flattening of villi X100.

the presence of severe stenosis at the duodenum, dilatation of the stomach and the retention of gastrointestinal juice (Figure 6). Because the patient's general condition was not deemed to be good enough to allow for additional chemo-radiotherapy or surgery, conservative endoscopic stenting was performed to dilate the lumen using a Wall Flex $^{\mathrm{TM}}$ Duodenal Stent (Boston Scientific Co. America) in order to relieve the symptoms that were considered to have been caused by the obstruction (Figure 7).

After the treatment, the symptoms of appetite loss and vomiting immediately disappeared, and oral intake was restored. The patient has been doing well for three months after undergoing this palliative procedure.

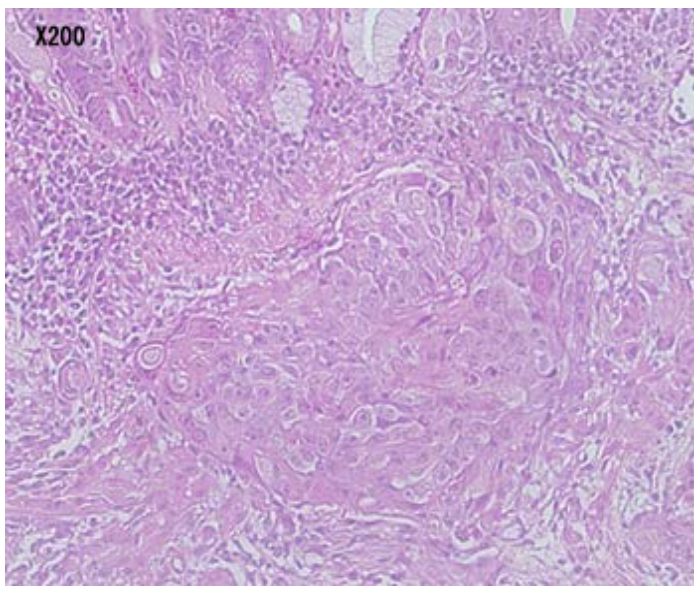

Figures 4: The histological findings of the duodenal metastasis from supraglottic laryngeal cancer. The histological findings of biopsy specimens obtained from the submucosal tumor showed moderately differentiated squamous cell carcinoma forming an alveolar pattern with an enlargement of the nucleus in tumor cells and a flattening of villi $X 200$.

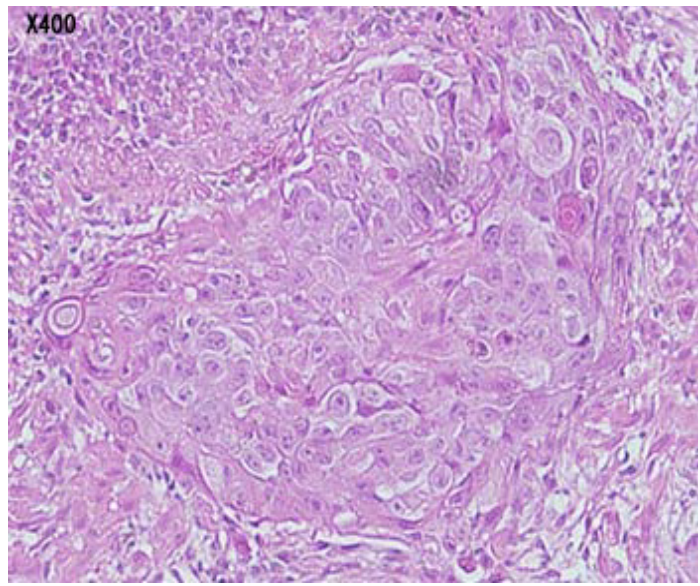

Figures 5: The histological findings of the duodenal metastasis from supraglottic laryngeal cancer. The histological findings of biopsy specimens obtained from the submucosal tumor showed moderately differentiated squamous cell carcinoma forming an alveolar pattern with an enlargement of the nucleus in tumor cells and a flattening of villi $\mathrm{X} 400$.

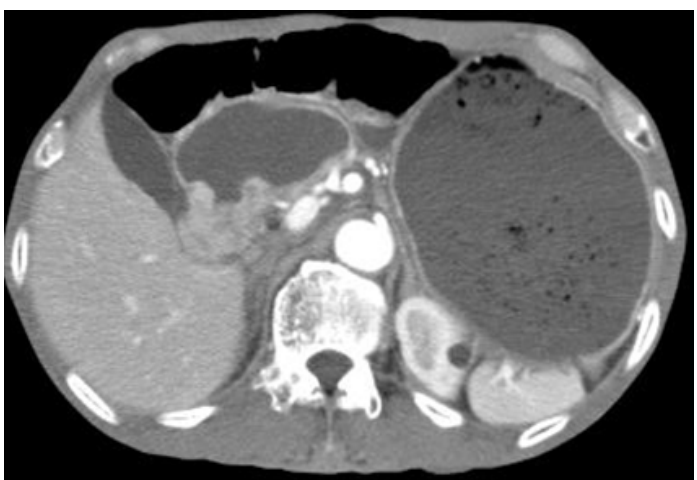

Figure 6: The computed tomography (CT) findings of duodenal metastasis from supraglottic laryngeal cancer. CT revealed the severe stenosis at the duodenum, dilatation of the stomach and the retention of gastrointestinal juice. 


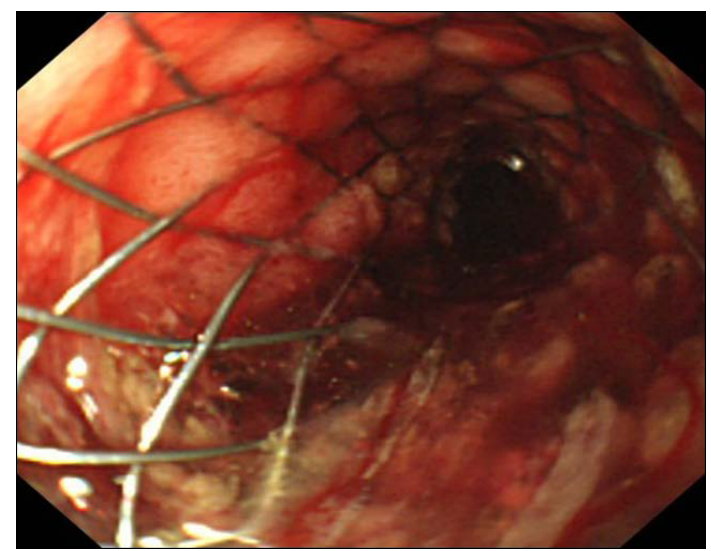

Figure 7: An endoscopic image of the conservative endoscopic stenting. A metallic stent was placed into the duodenum with the metastasis and severe circumferential stenosis using an endoscopic stenting technique. After the stenting, the symptoms of appetite loss and vomiting immediately disappeared, and oral intake was restored.

\section{Discussion}

We herein described a successful case of conservative endoscopic stenting for a rare duodenal metastasis from head and neck cancer with severe stricture. Most of the metastatic sites from head and neck tumors are in the lungs, bone and liver [3-9], and only five cases of small intestinal metastasis from such tumors have been reported in the English literature, including the present case (Table 1) [10-13].

The ages of the reported patients with duodenal metastasis from head and neck squamous cell carcinoma ranged from 54 to 71 years old, and all five patients were male. The stages at initial presentation were III in one case, IV in three cases and not described in one case. Surgery was chosen initially in four cases, radiotherapy was administered in four cases and chemotherapy was used for two cases. In four of the five cases, combination therapy with surgery, radiotherapy and/or chemotherapy was performed prior to the detection of the metastasis. The small intestinal metastasis was detected 10-13 months after the initial diagnosis. Gastrointestinal bleeding was present in two cases, intestinal obstruction in two cases and biliary obstruction was present in one case. The site of intestinal metastasis was the ileum in two cases, and the ampulla of Vater, jejunum and duodenum were affected in one case each. The lesion was treated surgically in two cases, and endobiliary stenting, endoscopic stenting and palliative chemotherapy were each performed in one case. Most cases exhibited a poor prognosis even after detection, and underwent surgery or stenting for the small intestinal metastasis.
Small bowel metastasis from head and neck squamous cell carcinoma is very unusual, and has been speculated to result from hematogenous dissemination [10] or an abnormality of the lymphovascular drainage. Small bowel metastases can also occur as a result of the transperitoneal spread from colorectal, ovarian, gastric and pancreatic tumors; however, no case of small intestinal metastasis from head and neck squamous cell carcinoma with peritoneal dissemination has been reported so far. Further accumulation of cases will elucidate the process of small intestinal metastasis from head and neck tumors.

Intestinal obstruction is the most severe complication in many advanced cancer patients, leading to the impairment of ingestion, the suspension of oral intake and the oral administration of therapy, a deterioration of the general condition and a decrease in the quality of life. Although surgery to remove the tumor responsible for the obstruction is considered to be the most effective treatment, many patients with small intestinal metastasis cannot undergo such operations due to their poor general status. In the present case, endoscopic stenting immediately improved the patient's symptoms and allowed restoration of his oral intake, suggesting that this endoscopic procedure is a practical option for the palliative relief of an intestinal obstruction in patients with such small intestinal metastasis.

As it is still controversial whether adjuvant chemotherapy with or without molecular targeted therapy contributes to the improvement of such intestinal metastasis [14-17], endoscopic stenting may be a promising choice of treatment. Further trials evaluating more patients with small intestinal metastasis are thus called for to establish the proper use of and indications for this treatment strategy.

In summary, we herein described a rare case of duodenal metastasis from supraglottic laryngeal cancer with a severe intestinal obstruction, which was dramatically relieved by palliative endoscopic stenting. When patients with head and neck tumors complain of gastrointestinal bleeding and/or symptoms associated with intestinal obstruction, then small intestinal metastasis might be present. Endoscopic stenting therefore appears to be a practical option for relieving the symptoms of such patients.

\section{References}

1. Rao DN, Shroff PD, Chattopadhyay G, Dinshaw KA (1998) Survival analysis of 5595 head and neck cancers--results of conventional treatment in a high-risk population. Br J Cancer 77: 1514-1518.

2. Hauswald H, Simon C, Hecht S, Debus J, Lindel K (2011) Long-term outcome and patterns of failure in patients with advanced head and neck cancer. Radiat Oncol 6: 70 .

3. Shah JP, Lydiatt W (1995) Treatment of cancer of the head and neck. CA Cancer J Clin 45: 352-368.

4. Kowalski LP, Carvalho AL, Martins Priante AV, Magrin J (2005) Predictive

\begin{tabular}{|c|c|c|c|c|c|c|c|c|c|}
\hline Age & Sex & $\begin{array}{l}\text { Site of primary } \\
\text { tumor }\end{array}$ & $\begin{array}{l}\text { Treatment of } \\
\text { primary tumor }\end{array}$ & $\begin{array}{l}\text { Interval between the } \\
\text { primary tumor and } \\
\text { intestinal metastasis }\end{array}$ & $\begin{array}{l}\text { Presentation } \\
\text { of intestinal } \\
\text { metastasis }\end{array}$ & $\begin{array}{l}\text { Site of intestinal } \\
\text { metastasis }\end{array}$ & $\begin{array}{l}\text { Treatment } \\
\text { of intestinal } \\
\text { metastasis }\end{array}$ & Results & $\begin{array}{l}\text { Reference } \\
\text { no }\end{array}$ \\
\hline 54 & M & Supraglottic larynx & T3N1M0 stage III & sX & 18 months & $\begin{array}{l}\text { Intestinal } \\
\text { bleeding/melena }\end{array}$ & lleum & Resection, anastomosis & 10 \\
\hline 71 & M & Supraglottic larynx & T4N0 stage IV & $S X+C T$ & 24 months & Obstruction & Ileum & Resection, anastomosis & 11 \\
\hline 71 & M & Vocal fold & ND & SX + PORT & 56 months & Biliary obstruction & Ampulla of vater & $\begin{array}{l}\text { Endobiliary stenting and } \\
\text { palliative CT }\end{array}$ & 12 \\
\hline 65 & M & Base of tongue & $\begin{array}{l}\text { T4N2cM0 stage } \\
\text { IV }\end{array}$ & $\mathrm{CT}+\mathrm{IMRT}$ & 10 months & $\begin{array}{l}\text { Melena/ intestinal } \\
\text { bleeding }\end{array}$ & Jejunum & Palliative CT & 13 \\
\hline 71 & M & Supraglottic larynx & T4N2M0 stage IV & SX + PORT & 13 months & Obstruction & Duodenum & $\begin{array}{l}\text { Endoscopic duodenal } \\
\text { stenting }\end{array}$ & Present case \\
\hline
\end{tabular}

ND: No Description, SX: Surgery, RT: Radiotherapy, PORT: Postoperative Radiotherapy, CT: Chemotherapy

Table 1: Reported cases of small bowel metastasis originating from primary head and neck squamous cell. Carcinoma 
Citation: Ando K, Fujiya M, Ueno N, Ikuta K, Kohgo Y (2014) Duodenal Metastasis from Head and Neck Cancer with an Intestinal Obstruction. J Cytol Histol S4: 016. doi:10.4172/2157-7099.S4-016

factors for distant metastasis from oral and oropharyngeal squamous cell carcinoma. Oral Oncol 41: 534-541.

5. Li X, Di B, Shang Y, Zhou Y, Cheng J, et al. (2009) Clinicopathologic risk factors for distant metastases from head and neck squamous cell carcinomas. Eur J Surg Oncol 35: 1348-1353.

6. Takes RP, Rinaldo A, Silver CE, Haigentz M Jr, Woolgar JA, et al. (2012) Distant metastases from head and neck squamous cell carcinoma. Part I. Basic aspects. Oral Oncol 48: 775-779.

7. Coca-Pelaz A, Rodrigo JP, Suárez C (2012) Clinicopathologic analysis and predictive factors for distant metastases in patients with head and neck squamous cell carcinomas. Head Neck 34: 771-775.

8. Airoldi M, Gabriele P, Succo G, Valente G, Brando V (1993) Small bowel metastasis from squamous cell carcinoma of the larynx. A case report. Tumori 79: 286-287.

9. Yoshihara T, Yamamura $Y$ (1997) An unusual case of laryngeal carcinoma metastasizing to the small intestine. J Laryngol Otol 111: 575-577.

10. Büyükçelik A, Ensari A, SarioÄŸlu M, IÅŸikdogan A, IÃ§li F (2003) Squamous cell carcinoma of the larynx metastasized to the ampulla of Vater. Report of a case. Tumori 89: 199-201.

11. Dwivedi RC, Kazi R, Agrawal N, Chisholm E, St Rose S, et al. (2010) Comprehensive review of small bowel metastasis from head and neck squamous cell carcinoma. Oral Oncol 46: 330-335.
12. Talmadge JE, Fidler IJ (2010) AACR centennial series: the biology of cancer metastasis: historical perspective. Cancer Res 70: 5649-5669.

13. Langley RR, Fidler IJ (2011) The seed and soil hypothesis revisited--the role of tumor-stroma interactions in metastasis to different organs. Int J Cancer 128 : 2527-2535.

14. Forastiere AA, Leong T, Rowinsky E, Murphy BA, Vlock DR, et al. (2001) Phase III comparison of high-dose paclitaxel + cisplatin + granulocyte colonystimulating factor versus low-dose paclitaxel + cisplatin in advanced head and neck cancer: eastern cooperative oncology group study E1393. J Clin Oncol 19: 1088-1095.

15. Gibson MK, Li Y, Murphy B, Hussain MH, DeConti RC, et al. (2005) Eastern Cooperative Oncology Group. Randomized phase III evaluation of cisplatin plus fluorouracil versus cisplatin plus paclitaxel in advanced head and neck cancer (E1395): an intergroup trial of the eastern cooperative oncology group. $\mathrm{J}$ Clin Oncol 23: 3562-3567.

16. Baselga J, Trigo JM, Bourhis J, Tortochaux J, Cortés-Funes H, et al. (2005) Phase II multicenter study of the antiepidermal growth factor receptor monoclonal antibody cetuximab in combination with platinum-based chemotherapy in patients with platinum-refractory metastatic and/or recurrent squamous cell carcinoma of the head and neck. J Clin Oncol 23: 5568-5577.

17. Vermorken JB, Mesia R, Rivera F, Remenar E, Kawecki A, et al. (2008) Platinum-based chemotherapy plus cetuximab in head and neck cancer. $\mathrm{N}$ Engl J Med 359: 1116-1127.
This article was originally published in a special issue, Histology and Histopathology handled by Editor(s). Borislav A. Alexiev, University of Maryland Medical Center, USA 